\title{
In family planning service programmes 'coordination' is greatly overrated
}

\author{
Philip D Harvey
}

DKT International, Washington, DC, USA

\author{
Correspondence to \\ Mr Philip D Harvey, DKT \\ International, $1701 \mathrm{~K}$ Street \\ NW, Suite 900, Washington, DC \\ 20006, USA; \\ phil@dktinternational.org
}

Received 15 July 2010 Accepted 5 October 2010
"We didn't get anything done this week. We were too busy coordinating."

Memo from Chinese family planning worker to his supervisor (2009)

Background

It has become almost axiomatic that family planning programmes should be coordinated and, to the extent possible, integrated with each other. I believe this is a mistake.

The use of contraceptives in the developing world has accelerated astonishingly in the past 30 years and, while government programmes remain very important, contraceptives and contraceptive services are increasingly supplied through a large variety of independently managed, generally uncoordinated activities. Attempts to coordinate these efforts, however well intentioned, tend to weaken them.

\section{Developing countries}

In most developing countries, particularly the poorest ones, couples get their contraceptives primarily from private sources. In Indonesia in 2007, for example, only $22 \%$ of modern method users relied on the public sector. ${ }^{1}$ The other $78 \%$, over 20 million couples, got their family planning from midwives, pharmacies and non-pharmacy stores, including a social marketing programme that today serves 5 million couples. In Bangladesh, a slight majority, 57\%, relied on public sources including government field workers in 2004, but the rest counted on pharmacies, shops and private clinics. In Cambodia (2005), modern method users relied on uncoordinated private sources $60 \%$ of the time. These included clinics, doctors, shops and community distributors. In the Dominican Republic (2002), more than half of the couples seeking birth control relied on the private sector. And in the Democratic Republic of Congo (2007), where usage is admittedly very low, $80 \%$ of family planning came from private sources, mostly pharmacies. Family planning in Uganda (2006) was $65 \%$ private.

\section{Pros and cons of coordination}

Should these activities be coordinated? I think not. For all the major private players - pharmaceutical companies, nongovernmental organisations (NGOs), social marketing projects, commercial salesmen and women, distribution and advertising firms - to be pulled under a single umbrella and integrated with each other would stifle and inhibit their efforts. Coordination usually means control by some central authority, normally the federal government or a committee with supervisory authority.

Such control slows things down, smothering energy and creativity. For family planning message content, for example, conformity to government norms would mean homogenisation of messages, less originality and reduced risk-taking. Advertising would be de-sexed. The need for additional approvals would slow marketing decisions and limit the provision of services. Far better that independent actors, working within the law and adhering to reasonable regulations, be permitted to get on with the job of providing an ever increasing variety of choices to an ever more demanding clientele. This is also the best way to see that consumers get the widest possible choice of methods and brands.

Donors often suggest that some coordination is necessary to prevent duplication and wastage. But free exchange of information generally solves this problem. If everyone has a reasonably good idea of what is being funded, duplication can be avoided. And integrating the activities of otherwise independent grantees almost invariably leads to homogenised (and slow) decision making and vitiation of energy and creativity, and is seldom worth it. If two parties offer similar family planning products or 
services, the worst that can happen is that consumers have more choice.

Coordinated programmes do not appear to be essential for high rates of contraceptive use. Brazil, with $70 \%$ contraceptive prevalence, has never had a centralised programme, for example. Indeed, most of South and Central America have had very few coordinated programmes for family planning. The citizens of those countries get their contraceptives largely from private commercial sources and, in a few cases from non-profit (private) sources like Colombia's PROFAMILIA and El Salvador's ADS.

\section{Government programmes}

This is not to denigrate government-run and government-sponsored programmes. Many Asian governments have persuaded their citizens to practise family planning, with salutary results. The government programme in Bangladesh, for example, has been a resounding success. After decades of effort, Bangladesh now boasts a modern method contraceptive prevalence rate of $48 \%$ and a total fertility rate of 2.5 , compared to $22 \%$ and 4.0 in Pakistan (a reasonable 'control' country), which has had no major government initiatives until very recently. But even in Bangladesh, the central programme was accompanied by a very large privately managed social marketing effort, largely uncoordinated with the government programme, and it was social marketing that dominated the radio and television airwaves for 20 years with colourful advertisements for Raja condoms, Ovacon pills, and the advantages of child spacing.

A related issue is donors' frequent insistence that local governments 'own' donor-sponsored family planning programmes in the private sector. Why? Developing country governments, particularly leftleaning ones, generally control too much private sector activity as it is. Why should the donor representatives of democratic, free-market countries want African or Asian governments to take ownership (and thus control) of private family planning? The US government does not 'own' Planned Parenthood. The British government does not want ownership of private groups like Marie Stopes International. Indeed, the private and independent nature of these groups is generally admired and encouraged by Western governments on their home turf. Why not follow similar polices in developing countries?

A good example of how government control can go wrong occurred in Vietnam, where the government, attempting to conform contraceptive social marketing activities to national policies, froze - for more than a decade - the selling price of contraceptives sold by DKT International at an artificially low price, refusing to let the prices of those products rise even by the cost of inflation. After 10 years, a major, five-fold increase was authorised, and the government threatened punitive action against DKT for not implementing the increase in a single, drastic step, a move that would have cut sales to near zero, eliminating an important source of condoms and oral contraceptives for Vietnamese consumers.

The United Nations is captivated by the lure of coordination. A recent United Nations Population Fund (UNFPA) "comprehensive condom programming" effort included a 10-step strategic approach meant to increase condom use. The programme called for establishment of a National Condom Support Team, which would include representatives from numerous ministries (health, finance, gender, tourism, education and so on), relevant regulatory authorities, various councils, the donor community, "civil society", social marketing representatives and private sector and business coalitions. The plan called for the development of a comprehensive and integrated national male/and female condom strategy, including a 5-year operational plan. Implementing such a strategy would mean dozens if not hundreds of meetings, reports, discussions and other unnecessary and expensive activities, resulting in the sort of organisation my colleague Tim Black has called "a bureaucratic dinosaur which must consume vast resources to maintain its metabolism, is slow in response and generates prodigious amount of wind". ${ }^{2}$ Why not instead, I suggested, just get out there and sell condoms? This idea was not found worthy by the authors of the plan.

\section{Concluding remarks}

We should celebrate diversity in family planning. The more parties that provide contraceptives, the better. Competition between providers, between brands of contraceptives and between different methods of delivery is healthy. Consumers are well served by this and they are demanding no less. If we're going to serve the contraceptive needs of an ever growing, and an ever more sophisticated population, we must let many (uncoordinated) flowers bloom. That is how our clients, including the poorest ones, will best be served.

\section{Competing interests None.}

Provenance and peer review Not

commissioned; externally peer reviewed.

\section{References}

1 Private sector percentage data are taken from the most recent Demographic and Health Surveys as summarised in issues of Studies in Family Planning (2005-2009).

2 Black T. Institutional checks to family planning. Fam Plann 1972;21:31-35. 